\title{
Metode Contextual Teaching anda Learning dapat Meningkatkan Hasil Belajar Agribisnis Ternak Unggas dengan Kompetensi Dasar Mengoperasikan Peralatan Farm pada Siswa Kelas X SMK Negeri 1
}

\author{
Raja Ampat
}

\author{
Zulkifli
}

SMK Negeri 1 Raja Ampat

\begin{abstract}
The background of this research is the result of learning achievement Basics of Livestock Maintenance in Class X SMK Negeri 1 Raja Ampat is still low with the average score obtained by students was $52 \%$. This study aims to improve the learning outcomes Basics of Livestock Maintenance with material Farm equipment operates using the method of Contextual Teaching and Learning (CTL) in students of class X SMK Negeri 1 Raja Ampat. The subjects of this study are all students of X Class of Department of Animal Husbandry SMK Negeri 1 Raja Ampat which amounted to 5 students. The obtained data were analyzed by using descriptive qualitative techniques. The pre-cycle results showed the learning result was $20 \%$ accomplished. On the cycle I, the accomplished students were 2 students $(60 \%)$ and on cycle II the all students could accomplish the test. The conclusion of this research is the method of Contextual Teaching Learning can improve the learning outcomes of Agribusiness of Poultry with competence in the students of class X SMK Negeri 1 Raja Ampat.
\end{abstract}

Keywords: contextual method, learning result, agribusiness of pultry, SMK Negeri 1 Raja Ampat

\begin{abstract}
Abstrak: Latar belakang penelitian ini adalah hasil pencapaian belajar Dasar-Dasar Pemeliharaan Ternak di Kelas X SMK Negeri 1 Raja Ampat masih rendah nilai rata-rata yang diperoleh siswa 52\%. Persentase ketuntasan siswa hanya $20 \%$ yang tuntas sedangkan yang belum tuntas mencapai $80 \%$. Penelitian ini bertujuan untuk meningkatkan hasil belajar Dasar-Dasar Pemeliharaan Ternak dengan materi Mengoperasikan peralatan Farm menggunakan metode Contextual Teaching and learning pada siswa kelas X SMK Negeri 1 Raja Ampat. Subyek Penelitian ini adalah seluruh Siswa Kelas X Jurusan Peternakan SMK Negeri 1 Raja Ampat yang berjumlah 5 orang siswa. Data yang diperoleh dianalisis dengan menggunakan teknik deskriptif kualitif. Hasil penelitian prasiklus menunjukkan hasil belajar dinyatakan tuntas sebanyak 1 siswa dengan persentase 20,\% sedangkan siswa yang belum tuntas 4 siswa dengan persentase $80 \%$. Untuk Siklus I dinyatakan tuntas sebanyak 2 siswa dengan persentase $40 \%$ sedangkan siswa yang belum tuntas 3 siswa dengan persentase 360 $\%$. Untuk siklus II dinyatakan semua siswa tuntas dengan persentase $100 \%$. Kesimpulan dari penelitian ini adalah metode Contextual Teaching anda Learning dapat meningkatkan hasil belajar Agribisnis Ternak Unggas dengan kompetensi pada siswa kelas X SMK Negeri 1 Raja Ampat.
\end{abstract}

Kata Kunci : metode kontekstual, prestasi belajar, agribisnis, ternak unggas, SMK Negeri 1 Raja Ampat

\section{Pendahuluan}

Pendidikan menengah kejuruan (SMK) merupakan ujung tombak dalam meningkatkan kualitas pendidikan, dengan mempersiapkan peserta didik yang terampil dan siap measuki lapangan kerja,dengan mengacu kepada kurikulum 2013. Diharapkan lulusan SMK ini 
mempunyai tingkat kompetensi dan keahlian sesuai profesi yang dimiliknya, hal ini tidak lepas dari peran guru.

Guru merupakan komponen pengajaran yang memegang peranan penting dan utama, karena keberhasilan proses belajar mengajar sangat ditentukan oleh factor guru. Tugas guru adalah menyampaikan materi pelajaran kepada siswa melalui interaksi komunikasi dalam proses belajar mengajar yang dilakukannya. Interaksi komunikasi, penerapan metode mengajar, dan pemakaian media pembelajaran yang baik dapat meningkatkan motivasi dan aktivitas siswa dalam proses belajar mengajar. Dengan demikian, diharapkan hasil belajar siswapun meningkat.

Berdasarkan uraian di atas nampak adanya kesenjangan antara kondisi nyata dengan harapan. Kesenjangan pokok dari subyek yakni pada kondisi awal hasil belajar siswa dalam materi peralatan farm sedangkan kondisi akhir yang diharapkan hasil belajar siswa dalam materi peralatan farm meningkat. Kesenjangan pokok dari peneliti yakni pada kondisi awal peneliti masih menyampaikan materi menggunakan model pembelajaran konvensional sedangkan kondisi akhir peneliti menggunakan menggunakan alat peraga . Jadi, upaya untuk memecahkan masalah dari kesenjangan yang terjadi adalah guru perlu menerapkan metode Contextual Teaching Learning (CTL). Kegiatan dilakukan secara mandiri, artinya siswa sesuai prosedur kerja diberi kebebasan untuk berkreasi sendiri dan tidak berada di bawah dikte guru.

\section{Metode Penelitian}

\subsection{Desain Penelitian}

Penelitian ini merupakan penelitian tindakan kelas menggunakan teori Kemmis dan Mc. Taggart. Penelitian ini dilaksanakan dalam 2 siklus. Masing-masing siklus terdiri dari perencanaan, tindakan, observasi dan refleksi.

\subsection{Subjek Penelitian}

Subjek dari penelitian ini adalah siswa dan guru mata pelajaran Agribisnis Ternak unggas Kelas X SMK Negeri 1 Raja ampat dengan jumalah siswa 5 Orang terdiri dari 2 siswa laki-laki dan 3 siswa perempuan yang memiliki latar belakang berbeda baik tempat tinggal, kemapuan orang tua, status sosial, daya serap prestasi dan hasil belajar.

\subsection{Tempat dan Waktu Penelitian}

Penelitian dilaksanakan di Kelas X SMK Negeri 1 Raja Ampat Kampung Samate, distrik Salawati Utara. Penelitian iini dilaksanakan dalam kurun waktu 1 bulan yakni pada bulan pertengahan September - Oktober 2017. 


\subsection{Teknik Pengumpulan Data}

Teknik pengumpulan data yang digunakan dalam penelitian ini adalah observasi, wawancara, tes, dan dokumentasi. Observasi ini ditujukan pada subjek peneliti yaitu guru dan siswa.

\subsection{Teknik Analisis Data}

Analisis data yang digunakan dalam penelitian ini dilakukan terus menerus selama pengumpulan data berlangsung sampai pada akhir penelitian atau penarikan kesimpulan. kriteria menghitung prestasi partisipasi siswa adalah sebagai berikut.

Tabel 1. Perentase Kriteria Aktivitas Siswa

\begin{tabular}{ll}
\hline Persentase & Kriteria aktivitas Siswa \\
\hline $80 \%-100 \%$ & Sangat Baik \\
$61 \%-80 \%$ & Tinggi \\
$41 \%-60 \%$ & Sedang \\
$21 \%-40 \%$ & Rendah \\
$0 \%-20 \%$ & Sangat Rendah \\
\hline
\end{tabular}

(Riduwan,2009:15)

Untuk mengatahui penignkatan prestasi siswa, peneliti menggunakan Kriteria Ketuntasan Minimal (KKM) pada mata pelajaran Agribisnis Ternak unggas, yaitu 70. Bila siswa telah mencapai nialai sama atau lebih besar dari 70 dengan prosedur rentang nilai 0 100 maka dapat dikatakan melewati KKM ( tuntas). Sedangkan siswa yang nilai kurang dari 70 maka dikatakan masih dibawah KKM (Belum tuntas).

\section{Hasil dan Pembahasan}

\subsection{Hasil Penelitian}

Tabel 3.1.Daftar Nilai Pembelajaran Dasar-Dasar Pemeliharaan Ternak Prasiklus

\begin{tabular}{llll}
\hline No. & Nama Siswa & Nilai & Keterangan \\
\hline 1. & ADRIYANA MANUFANDU & 45 & Tidak tuntas \\
2. & KARLOS YOAP KLAWEN & 40 & Tidak Tuntas
\end{tabular}




\begin{tabular}{llll} 
3. & RAHMI GAMAN & 70 & Tuntas \\
4. & RATZ FAUZAN RAPPY & 50 & Tidak Tuntas \\
5. & RISTA RAHMAN & 55 & Tidak Tuntas \\
\hline Jumlah Nilai & 260 & \\
\hline Rata-Rata Nilai & 52 & \\
\hline Nilai Tertinggi & 70 & \\
\hline Nilai Terendah & 40 & \\
\hline
\end{tabular}

Berdasarkan dari tabel diatas hasil belajar siswa pada prasiklus diperoleh data 3 siswa dengan prosentase $60 \%$ mendapat nilai rendah, 1 siswa dengan prosentase $20 \%$ mendapat nilai sangat rendah, 1 siswa dengan prosentase $20 \%$ mendapat nilai sedang. Artinya bahwa hasil belajar belum tercapai sepenuhnya, untuk itu perlu diadakan perbaikan pembelajaran. Perbaikan pembelajaran yang akan dilakukan untuk menindak lanjuti adalah dua siklus yaitu siklus I dan siklus II.

Adapun hasil belajar yang diperoleh pada siklus I adalah sebagai berikut:

Tabel 3.2. Daftar Nilai Pembelajaran Siklus I

\begin{tabular}{llcl}
\hline NO. & NAMA SISWA & NILAI & KETERANGAN \\
\hline 1. & ADRIYANA MANUFANDU & 60 & Tidak Tuntas \\
2. & KARLOS YOAP KLAWEN & 60 & TidakTuntas \\
3. & RAHMI GAMAN & 80 & Tuntas \\
4. & RATZ FAUZAN RAPPY & 70 & Tuntas \\
$5 . \quad$ RISTA RAHMAN & 60 & Tidak Tuntas \\
\hline Jumlah Nilai & 330 & \\
\hline \multicolumn{2}{l}{ Rata-Rata } \\
Nilai Tertinggi & 66 & \\
\hline Nilai Terndah & 50 \\
\hline
\end{tabular}

Tabel 3.3. Persentase Hasil Siklus I

\begin{tabular}{lccc}
\hline Kriteria & Rentang Nilai & Jumlah Nilai & Porsentase \\
Sangat Tinggi & $90-100$ & 0 & 0 \\
Tinggi & $75-89$ & 1 & $20 \%$ \\
Sedang & $60-74$ & 1 & $20 \%$ \\
Rendah & $45-59$ & 3 & $60 \%$ \\
Sangat rendah & $0-44$ & 0 & $0 \%$ \\
\hline
\end{tabular}


Grafik 1. Hasil Pemberlajaran Dasar-Dasar Agribisnis Ternak Siklus I.

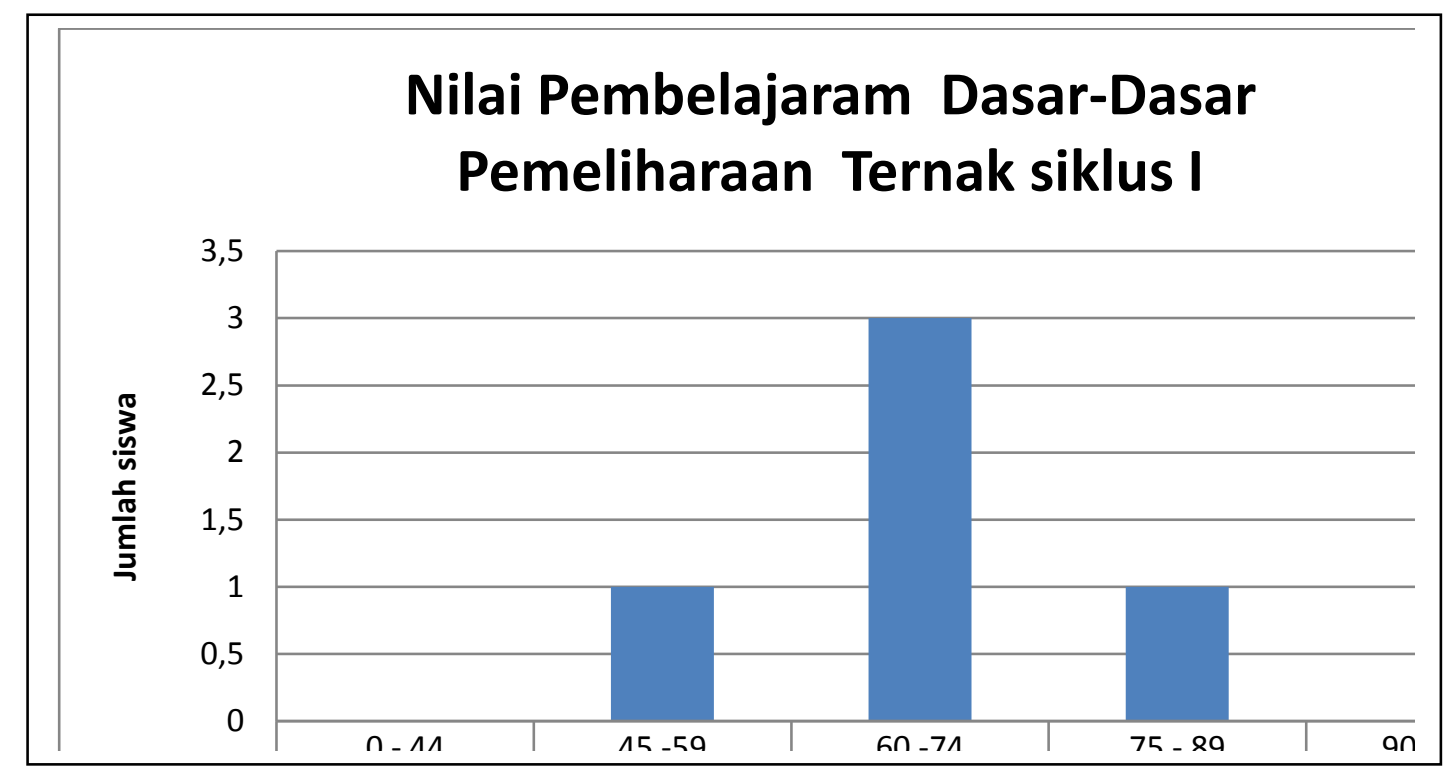

Berdasarkan tabel dan grafik diatas dari hasil belajar siswa pada siklus I diperoleh data 1 siswa dengan prosentase $20 \%$ mendapat nilai rendah siswa dengan prosentase $40 \%$ sedang , 1 siswa dengan prosentase $20 \%$ tinggi. Dari data tersebut dapat diartikan bahwa hasil belum sepenuhnya tercapai, untuk itu perlu diadakan perbaikan pembelajaran. Perbaikan pembelajran dilakukan untuk menindak lanjuti hal tersebut dengan siklus II.

Hasil belajar pada siklus II pembelajaran sudah meningkat karena terjadi peningkatan nilai diatas kriteria ketuntasan minimal pada kompetensi dasaar mengoperasikan peralatan farm pada siswa kelas X Jurusan peternakan SMK Negeri 1 Raja ampat. Adapun hasil belajar yang diperoleh pada siklus II adalah sebagai berikut :

Tabel 3.4 Daftar Nilai Pembelajaran Siklus II

\begin{tabular}{llcl}
\hline NO. & NAMA SISWA & NILAI & KETERANGAN \\
1. & ADRIYANA MANUFANDU & 80 & Tuntas \\
2. & KARLOS YOAP KLAWEN & 70 & Tuntas \\
3. & RAHMI GAMAN & 90 & Tuntas \\
4. & RATZ FAUZAN RAPPY & 85 & Tuntas \\
5. & RISTA RAHMAN & 90 & Tuntas \\
\hline Jumlah Nilai & 415 & \\
\hline
\end{tabular}




\begin{tabular}{ll}
\hline Rata-Rata & 83 \\
\hline Nilai Tertinggi & 90 \\
\hline Nilai Terndah & 70 \\
\hline
\end{tabular}

Tabel 3.5. Prosentase Hasil Pembelajaran Siklus II

\begin{tabular}{lccc}
\hline Kriteria & Rentang Nilai & Jumlah Nilai & Porsentase \\
Sangat Tinggi & $90-100$ & 2 & $40 \%$ \\
Tinggi & $75-89$ & 2 & $40 \%$ \\
Sedang & $60-74$ & 1 & $20 \%$ \\
Rendah & $45-59$ & 0 & $0 \%$ \\
Sangat rendah & $0-44$ & 0 & $0 \%$ \\
\hline & Jumlah & 5 & $100 \%$ \\
\hline
\end{tabular}

Gambar 2. Grafik Siklus II

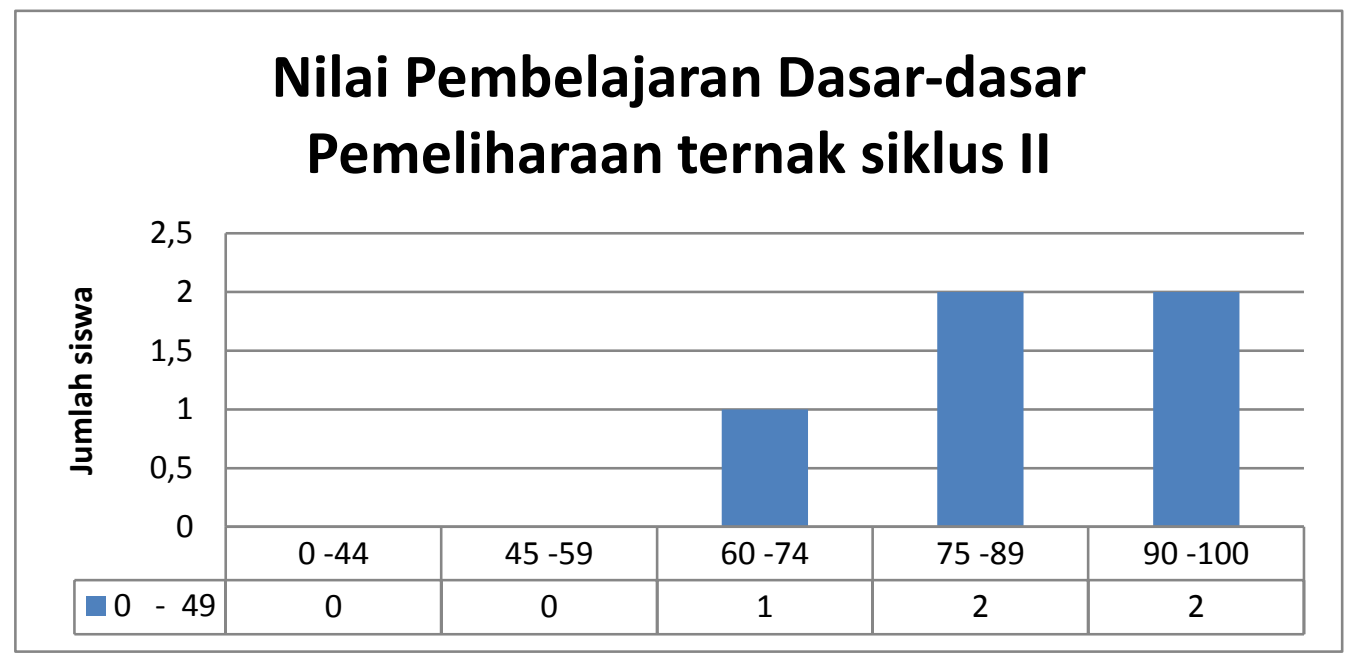

Berdasarkan dari tabel dan grafik analisis nilai hasil belajara siswa pada siklus II di peroleh data tidak ada siswa yang mendapat nilai sangat rendah dengan prosentase $0 \%$. siswa mendapat nilai rendah dengan 0 persentase. Hasil belajar dari ke 5 siswa mendapat nilai diatas KKM dengan persentase $100 \%$ sedangkan 1 siswa hanya 70 nilai belajar sedang. Jadi kelima siswa pada siklus II tuntas semua.

Dengan demikian perbaikan pembelajaran cukup sampai siklus II. Setelah permasaalahan utama pada perbaikan pada siklus I dan II dilaksanakan penulis sudah puas dengan meningkatnya hasil belajar siswa pada pelaksanaan perbaikan pembelajaran pada siklus II. 


\subsection{Pembahasan}

Berdasarkan hasil diskusi dengan teman sejawat, Pembelajaran yang rendah setelah dilaksanakan Perbaikan sudah ada peningkatan. Pada kegiatan prasiklus dengan menggunakan meotede ceramah siswa belum sepenuhnya memahami materi yang dipelajari, sekedar pemahaman singkat sehingga dapat disimpulkan bahwa rata-rata yang didapat siswa belum sesuai dengan kriteria ketuntasan minimal pada siswa kelas X Jurusan Peternakan pada SMK Negeri 1 Raja Ampat.

Pada kegitan pra siklus rata-rata nilai yang didapat adalah hasil belajar siswa dengan katagori sangat rendah dengan rentang nilai 0 - 44 dengan prosentase $20 \%$ sebanyak 1 siswa, hasil belajar dengan katagori rendah dengan rentang nilai 45 - 59 dengan prosentase $60 \%$ dengan jumlah siswa 3 orang. Hasil belajar siswa dengan katagori sedang dengan rentang nilai 60 - 74 dengan prosentase $20 \%$ dengan jumlah siswa 1 , hasil belajar siswa dengan katagori 75-89 dengan prosentase $0 \%$ dengan jumlah siswa 0 orang. Hasil belajar dengan katagori 90 - 100 dengan prosentase $0 \%$ yang telah mencapai kriteria ketuntasan Minimal (KKM) 1siswa dari 5 siswa dengan prosentase $20 \%$. sedangkan siswa yang belum tuntas 4 siswa dengan prosentase $80 \%$, sehingga perlu diadakan perbaikan.

Pada kegiatan perbaikan pembelajaran siklus I yang telah menerapkan Metode pembelajaran Menggunakan Contekstual Learning telah terjadi peningkatan hasil belajar dari evaluasi sebelumnya, hal ini terlihat dari kenaikan rata-rata nilai hasil belajar siswa yang pra siklus mencapai 52 sedangkan siklus I mencapai 66. Pada kegiatan perbaikan pembelajaran siklus I rata-rata hasil belajar siswa katagori sedang. Adapun rentang nilai yang diperoleh 044 dengan prosentase $0 \%$, hasil belajar dengan katagori rendah dengan rentang nilai 45 - 59 dengan prosentase $20 \%$ dengan jumlah siswa 1 orang. Hasil belajar siswa dengan katagori sedang dengan rentang nilai 60 - 74 dengan prosentase $60 \%$ dengan jumlah siswa 3 , hasil belajar siswa dengan katagori 75-89 dengan prosentase $20 \%$ dengan jumlah siswal orang . Hasil belajar dengan katagori 90 - 100 dengan prosentase $0 \%$ yang telah mencapai kriteria ketuntasan Minimal (KKM) 1 siswa dari 5 siswa dengan prosentase 20\% . sedangkan siswa yang belum tuntas 4 siswa dengan prosentase $80 \%$, sehingga perlu diadakan

Pada perbaikan siklus II terjadi peningkatan hasil belajar yang signifikan hal ini terbukti dengan adanya perubahan. Berdasarkan hasil perbaikan pembelajran siklus I dan siklus II penelitian I ni secara garis besar sudah ada peningkatan hasil belajar sisiwa dengan menggunakan metode Contekstual Learning pada kompentensi Mengoperasikan Peralatan Farm ( Pemanas Serbuk Gergaji) Dengan menggunakan metode pada kompetensi dasar 
mengoperasikan peralatan farm terjadi peningkatan hasil belajar siswa, maka dari proses penelitian perbaikan pembelajaran penulis cukupkan sampai pada siklus II, Karen pada siklus ini hasil belajar siswa sudah mencapai KKM atau hasil belajar yang baik.

\section{Simpulan dan Saran}

\subsection{Kesimpulan}

Penerapan metode Contekstual Learning dapat meningkatkan aktifitas, partisifasi dan hasil belajar siswa Pada Pelajaran Dasar-Dasar Pemeliharaan ternak dengan kompentensi dasar Mengoperasikan peralatan farm dengan sub materi Mengoperasikan Pemanas Serbuk Gergaji pada siswa Kelas X Jurusan Peternakan SMK Negeri 1 Raja Ampat.

\subsection{Saran}

1. Guru

a. Menerapkan metode Contekstual learning untuk meningkatkan hasil dasardasar Pemeliharaan ternak, dengan kometensi Dasar Mengoperasikan peralatan farm.

b. Hendaknya dalam menjelaskan materi menggunakan bahasa yang mudah dimengerti siswa.

2. Siswa Sebaiknya

a. Memamfaatkan fasilitas perpustakaan untuk menambah referans pembelajaran

b. Sering melakukan diskusi dan Tanya jawab sesama teman agar pemahaman mateteri lebih mendalam.

c. Sekolah/pemerintah sebagai pengambil kebijakan pendidikan sebaiknya :

1. Pengawas dan Kepala Sekolah hendaknya aktif melakukan suvervisi terhadap kelas-kelas secara terencana agar memperoleh data hasil belajar siswa.

2. Meningkatkan sarana dan prasarana yang memadai untuk menunjang keberhasilan proses belajar mengajar.

3. Meningkatkan kualifikasi tenaga kependidikan yang professional khususnya pada jenjang pendidikan SMK

\section{Daftar Pustaka}

Bloom, Benyamin S. 1986. Taxonomy of Education Objective. New York: Longman. 
Djamah Sopah. 2001. Pengembangan dan Penggunaan Model Pembelajaran ARIAS, http://www.depdiknas.go.id./Jurnal/31/djamah sopah.htm.

JP. Chaplin. 1992. Psikologi Pengajaran. Jakarta : Pustaka Jaya.

Mochtar Buchari. 1986. Dasar-dasar Kependidikan. Bandung : Tarto

Nasution. 1972. Psikologi Pengajaran Nasional. Bandung : Remaja Rosda Karya.

Rochman Nata Wijaya. 1992. Penelitian untuk Ilmu-ilmu Perilaku. Bandung : Remaja Rosda Karya

Slameto. 1998. Didaktik Metodik. Jakarta : Pustaka Jaya.

Suharsimi Arikunto. 1996. Prosedur Penelitian: Suatu Pendekatan Praktek. Jakarta : Rhineka Cipta.

The Liang Gie. 2000. Kamus Psikologi. Jakarta : PN. Balai Pustaka.

Toeti Soekamto dan Udin Saripudin Winataputra, 1997, Teori Belajar dan Modelmodel Pembelajaran, Jakarta : PAU Ditjen Dikti Depdikbud

Tutik, dkk. 2013. Dasar-Dasar Pemeliharaan Ternak. PPPTK Cianjur Kementerian 